\title{
Horizon 2020
}

\section{The next European Union funding scheme, which is pending European Council and Parliament approval by summer 2013, will be dedicated to both research and innovation.}

Advanced materials fall within the Key Enabling Technologies listed as priorities of the forthcoming eighth framework programme (FP8), dubbed Horizon 2020 $(\mathrm{H} 2020)^{1}$. This is the new European Union funding scheme endowed with $€ 80$ billion, representing $7-8 \%$ of the Union's budget to be spent between 2014 and 2020. This constitutes a welcome budget increase of $46 \%$ compared with FP7 (ref. 2).

The budget is set aside for investment in both research and innovation, with a respective allocation of $€ 24$.6 billion to support 'excellent science' and $€ 17.9$ billion for 'industrial leadership' in innovation. This joined-up thinking in the funding model is one of the novelties of the programme. The programme pledges to focus on turning scientific breakthroughs into innovative products and services. To do so, it claims it will provide seamless and coherent funding from idea to market.

The focus on innovation could prove an attractive proposition for materials scientists, especially those involved in applied research. Horizon 2020 concentrates on industrial sectors such as advanced materials and nanotechnology in addition to information and communication technologies (ICT), biotechnology, advanced manufacturing and space. Ultimately, the $\mathrm{H} 2020$ goal is to attract a higher number of industry participants than the $29 \%$ taking part in FP7 - a drop compared with $34 \%$ participation in the previous programme FP6.

The other key objective of the programme is to support research excellence. It will concentrate a higher amount of resources in basic research than ever before to help Europe face up to the mounting pressure of international competition. A dedicated budget of $€ 13.2$ billion will be allocated to the elitist and highly selective European Research Council (ERC), which will see its funding increase by $77 \%$ compared with FP7. Such an increase goes against current national economic trends of austerity plans emerging throughout Europe.

Clearly, any effort to centralize research funding throughout the ERC to avoid duplication of efforts has to be commanded in line with the philosophy of the European Research Area. Meanwhile, the simplification of funding rules and

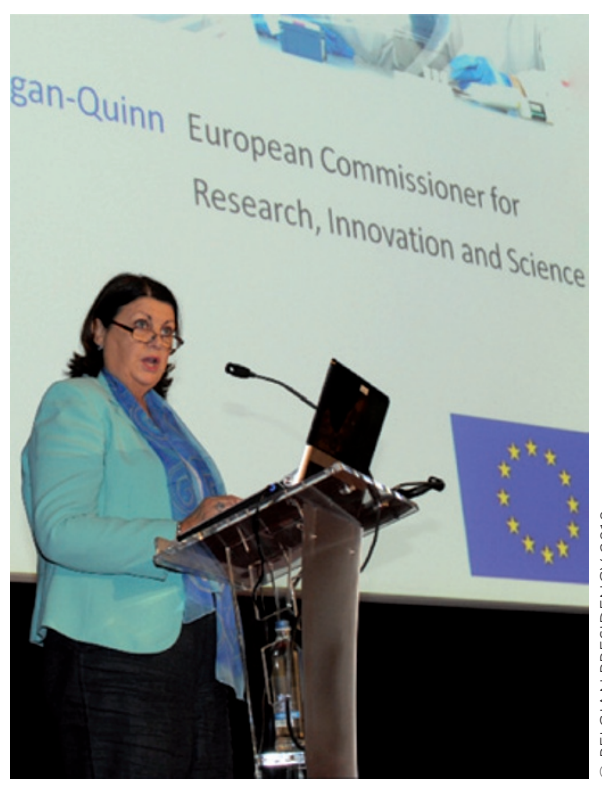

European Commissioner for Science, Innovation and Research, Máire Geoghegan-Quinn, will have a role to play in ensuring the success of Horizon 2020.

procedures should enhance access to such funding. Horizon 2020 proposes to introduce a single point of access for participants, to cut red tape for proposals, and pledges to perform no unnecessary controls and audits. For example, the programme plans to drastically simplify reimbursement by introducing a single flat rate for indirect costs and only two funding rates: one for research (20\% to complement, $100 \%$ direct costs reimbursement) and one for close-to-market activites (20\% to complement, $70 \%$ direct costs reimbursement). Another objective is to reduce the funding allocation time by 100 days on average, from 350 to 250 days, to ensure the prompt start of projects. In principle, such a remedy to previous framework programmes' blatant deficiencies can only be welcome.

Yet, in an attempt to search for efficiencies with an elitist approach, there is always a risk that some scientists may feel left out. Nevertheless, the European Commission is aware that their approach needs to be complemented with measures to support new entrants with riskier projects.
Horizon 2020 thus plans an "inclusive approach open to new participants, including those with ideas outside of the mainstream." Time will tell whether such noble intentions are effectively implemented.

In addition to the increased concentration of resources, what constitutes a change in H2020 is that it encourages funding models that are "science-driven and largely bottomup and investigator-initiated," as advocated by Máire Geoghegan-Quinn, European Commissioner for Research, Innovation and Science $^{3}$. The idea is to strike a balance with the top-down thematic approach of previous European Union FPs, which allocated funding according to predefined thematic areas, by supporting a limited number of focal areas.

Finally, the third key objective of H2020 is to fund multidisciplinary solutions to address 'societal challenges' in health, food, energy, transport, climate and security. Concern affecting European citizens often needs to be tackled at the global level through international research cooperation. However, some like scientists' lobbying group Euroscience ${ }^{4}$, regret that the proposed H2020 programme lacks a strategic approach to such international cooperation, which could have been done along the lines of science diplomacy.

Regardless of criticisms, embracing societal concerns represents a great shift in thinking of H2020. By adopting such a big picture approach the European Commission has demonstrated its ability to renew its social vows. It also means it is adopting an outside-the-box guiding principle for the allocation of funds. This should be attractive for materials scientists who will have the opportunity to directly or indirectly contribute technological solutions to some of the greater societal issues such as healthcare (drug delivery, tissue engineering and stem cell differentiation), and sustainable energy storage (batteries) and production (photovoltaics).

\footnotetext{
References

1. http://ec.europa.eu/research/horizon2020

2. Nature Mater. 9, 463 (2010).

3. Annual Report on the ERC Activities and Achievements in 2011 (European Commission, 2012); http://erc.europa.eu/sites/default/ files/document/file/erc_annual_report_2011.pdf

4. Science's Position on the Horizon 2020 - the EU Framework for Research and Innovation (Euroscience, January 2012); http://www.euroscience.org
} 